\title{
Wine glass size and wine sales: four replication studies in one restaurant and two bars
}

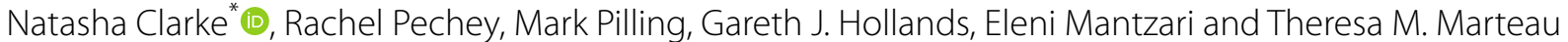

\begin{abstract}
Objective: Previous research suggests that wine glass size affects sales of wine in bars, with more wine purchased when served in larger glasses. The current four studies, conducted in one restaurant (Studies 1 and 2) and two bars (Studies 3 and 4) in Cambridge, England, aim to establish the reproducibility of this effect of glass size on sales. A multiple treatment reversal design was used, involving wine being served in sequential fortnightly periods in different sized glasses of the same design ( $290 \mathrm{ml}, 350 \mathrm{ml}$, and $450 \mathrm{ml})$. The primary outcome was daily wine volume (ml) sold.

Results: Restaurant: Daily wine volume sold was 13\% (95\% Cl 2\%, 24\%) higher when served with $350 \mathrm{ml}$ vs. $290 \mathrm{ml}$ glasses in Study 1. A similar direction of effect was seen in Study 2 (6\%; 95\% Cl - 1\%, 15\%). Bars: Daily wine volume sold was 21\% (95\% Cl 9\%, 35\%) higher when served with $450 \mathrm{ml}$ vs. $350 \mathrm{ml}$ glasses in Study 3. This effect was not observed in Study $4(-7 \%, 95 \% \mathrm{Cl}-16 \%, 3 \%)$. Meaningful differences were not demonstrated with any other glass comparison. These results partially replicate previous studies showing that larger glasses increase wine sales. Considerable uncertainty remains about the magnitude of any effect and the contexts in which it might occur.
\end{abstract}

Trial registration Study 1: ISRCTN17958895 (21/07/2017), Study 2: ISRCTN17097810 (29/03/2018), Study 3 and 4: ISRCTN39401124 (10/05/2018)

Keywords: Wine, Alcohol, Sales, Purchasing, Glass size, Replication, Multiple treatment reversal design, Bar, Restaurant

\section{Introduction}

Alcohol consumption is a leading risk factor for global disease burden worldwide [1] and is the fifth leading factor in the UK [2]. One potential intervention to reduce alcohol consumption is to change the size of glassware [3]. Larger glasses may increase consumption by two means. First, by influencing pouring behaviour, with larger glasses resulting in more alcohol being poured into them $[4,5]$. Second, by influencing perceptions of volume, with the same volume of alcohol being perceived as less when poured into larger compared with smaller glasses [6]. As people tend to consume in units-one glass of wine, one slice of cake-known as "the unit bias

\footnotetext{
*Correspondence: ncc42@medschl.cam.ac.uk
}

Behaviour and Health Research Unit, University of Cambridge,

Cambridge, UK heuristic" [7], if a serving of wine is perceived as less than a glass it could lead some people to drink another glass.

This replication paper extends previous studies that indicate an effect of glass size on sales, a proxy measure of consumption, in restaurant and bar settings in Cambridge, England $[8,9]$. The first of these studies, carried out in a single establishment that had separate bar and restaurant areas, found that serving wine in larger (370 ml capacity) compared with medium-sized $(300 \mathrm{ml})$ glasses, keeping serving size constant, increased wine sales by $9.4 \%$. This difference in sales was $14.3 \%$ in the bar area, compared to a non-significant difference of $8.2 \%$ in the restaurant. Results were inconclusive when comparing sales using smaller glasses $(250 \mathrm{ml})$ with mediumsized glasses $(300 \mathrm{ml})$ [8].

The second study was carried out in two bars and used glass sizes with capacities of $300 \mathrm{ml}, 370 \mathrm{ml}, 510 \mathrm{ml}$ (Bar 1) and $300 \mathrm{ml}$ and $510 \mathrm{ml}$ (Bar 2). In Bar 1, daily wine 
volume purchased was $11 \%$ higher when sold in $510 \mathrm{ml}$ compared to $370 \mathrm{ml}$ glasses. Findings were inconclusive for the other glass comparisons [9]. These results provided a partial replication of the initial study, showing that introducing larger glasses increased sales. However, the pattern of results was mixed, which could reflect a moderating influence, such as the serving size selected, characteristics of the establishment, such as differences in sales by bottle vs. glass, or random fluctuations rather than true effects. The current paper aims to establish the reproducibility of an effect of glass size on sales in four studies, conducted in one restaurant and two bars in England.

\section{Main text \\ Methods}

\section{Study design}

Wine glasses of different sizes i.e. bowl capacities, were changed over fortnightly periods in each establishment in a multiple treatment reversal design using $290 \mathrm{ml}, 350 \mathrm{ml}$ and $450 \mathrm{ml}$ glasses (see Table 1). The primary outcome was the daily volume of wine $(\mathrm{ml})$ sold. Reference groups were $290 \mathrm{ml}$ for the restaurant and $350 \mathrm{ml}$ for the bars.

\section{Intervention}

The glasses used were of the same design (Royal Leerdam Bouquet), with capacities of $290 \mathrm{ml}, 350 \mathrm{ml}$ and $450 \mathrm{ml}$. These were of a slightly different design and larger

Table 1 Glass capacity (ml) by fortnightly period for each study

\begin{tabular}{lllll}
\hline Fortnight & $\begin{array}{l}\text { Study 1 } \\
\text { (Restaurant A) }\end{array}$ & $\begin{array}{l}\text { Study 2 } \\
\text { (Restaurant A) }\end{array}$ & $\begin{array}{l}\text { Study 3 } \\
\text { (Bar A) }\end{array}$ & $\begin{array}{l}\text { Study 4 } \\
\text { (Bar B) }\end{array}$ \\
\hline 1 & 290 & 290 & 350 & 350 \\
2 & 350 & 350 & 290 & 290 \\
3 & $290^{\mathrm{a}}$ & 290 & 350 & 350 \\
4 & 450 & 450 & 450 & $450^{\mathrm{b}}$ \\
5 & 290 & 290 & 350 & 350 \\
6 & 350 & 350 & 290 & 290 \\
7 & 290 & 290 & $350^{\mathrm{b}}$ & 350 \\
8 & 450 & $450^{\mathrm{b}}$ & 450 & 450 \\
9 & 290 & 290 & 350 & 350 \\
10 & & 350 & & \\
11 & & 290 & & \\
12 & & 450 & & \\
13 & & 290 & & \\
\hline
\end{tabular}

a Following Fortnight 3, there was an excluded 2-week period for Study 1, when $230 \mathrm{ml}$ glasses (rather than the $450 \mathrm{ml}$ ) were introduced to better match the glasses in the initial study on wine glass size (7), but these were withdrawn following customer complaints

b Due to fidelity check violations (i.e. glasses not changed over on time), these periods lasted 3 weeks with establishments continuing to use this glass size for one extra week, although these additional weeks were not included in analyses capacities than glasses used in the initial study [8] (Royal Leerdam Fortius $250 \mathrm{ml}, 300 \mathrm{ml}$ and $370 \mathrm{ml}$ ) due to the range being discontinued. The sizes compared in the different settings were constrained by the serving sizes offered in the participating establishments.

In keeping with UK law [10], serving sizes offered were not altered. All establishments offered wine by the glass in $125 \mathrm{ml}$ and $175 \mathrm{ml}$ serving sizes and $75 \mathrm{cl}$ bottles. The restaurant also offered wine in $50 \mathrm{cl}$ and $100 \mathrm{cl}$ carafes. The $75 \mathrm{cl}$ bottles and $50 / 100 \mathrm{cl}$ carafes were free-poured into glasses by bar staff or customers. The bars-but not the restaurant-also offered wine in $250 \mathrm{ml}$ serving sizes.

Changing the size of wine glasses is categorised as a Size $\times$ Product intervention within the TIPPME (Typology of Interventions in Proximal Physical Micro-Environments) [11].

\section{Setting}

The study was conducted in one independent restaurant (Study 1 and 2) and two bars from the same pub group (Study 3 and 4) in Cambridge, England. One size of wine glass was used at any one time for all wine sold regardless of serving size, with the exception of sparkling wines, sales of which were excluded from the current studies. See Table 2 for establishment characteristics.

\section{Procedure}

Glasses were changed by bar or restaurant staff in each of the participating establishments on Monday mornings each fortnight throughout the study period. Email reminders were sent by a researcher at $8 \mathrm{a} . \mathrm{m}$. on the morning of a glass changeover. The manager of each establishment was asked to confirm that the glass change had occurred prior to opening that day. Fidelity to protocol was checked by a researcher visiting the restaurant or bar at the start of each fortnightly period. The check involved a person from the research group acting as a customer and first, checking that the glasses in the bar area were all of the same design and second, buying a small glass of wine $(125 \mathrm{ml})$. The checker then measured the height of the wine glass to ensure it matched the scheduled glass size. In the case of violations, the lead researcher contacted the manager to report the violation. Glass changeover then took place as soon as possible, and the actual date of changeover recorded. If the establishment's manager could not be reached to confirm when a changeover occurred following a protocol violation, that week's data was not included in analyses, and the establishment continued using the affected glass size for one extra week assuming the next fidelity checks were passed. Sales data were obtained from the till records of each venue. 
Table 2 Characteristics of participating establishments

\begin{tabular}{|c|c|c|c|c|c|c|c|}
\hline & \multicolumn{3}{|l|}{ Previous studies } & \multicolumn{4}{|l|}{ Current studies } \\
\hline & \multirow{2}{*}{$\begin{array}{l}\text { Bar } \\
\text { and restaurant } \\
\text { Pechey et al. [8] }\end{array}$} & \multirow{2}{*}{$\begin{array}{l}\text { Bar } 1^{\mathrm{a}} \\
\text { Pechey et al. [9] }\end{array}$} & \multirow[t]{2}{*}{ Bar 2} & \multicolumn{2}{|l|}{ Restaurant A } & \multirow{2}{*}{$\begin{array}{l}\text { Bar A } \\
\text { Study } 3\end{array}$} & \multirow{2}{*}{$\begin{array}{l}\text { Bar B } \\
\text { Study } 4\end{array}$} \\
\hline & & & & Study 1 & Study 2 & & \\
\hline $\begin{array}{l}\text { Standard glass } \\
\text { size }(\mathrm{ml})\end{array}$ & 300 & 350 & 350 & $310^{\mathrm{b}}$ & $350^{c}$ & 350 & 350 \\
\hline $\begin{array}{l}\text { Intervention } \\
\text { glass sizes (ml) }\end{array}$ & $250,300,370$ & $300,370,510$ & 300,510 & $290,350,450$ & $290,350,450$ & $290,350,450$ & $290,350,450$ \\
\hline $\begin{array}{l}\text { Price of } 175 \mathrm{ml} \text { of } \\
\text { wine }(£)\end{array}$ & 5.00 & 4.10 & 5.40 & 5.90 & 5.90 & 5.21 & 4.34 \\
\hline \multicolumn{8}{|c|}{ Serving sizes offered (ml) } \\
\hline Fixed & 125,175 & $125,175,250$ & $125,175,250$ & 125,175 & 125,175 & $125,175,250$ & $125,175,250$ \\
\hline Free-poured & $500,750,1000$ & 750 & 750 & $500,750,1000$ & $500,750,1000$ & 750 & 750 \\
\hline $\begin{array}{l}\text { Sales by-the- } \\
\text { glass (\%) }\end{array}$ & $\begin{array}{l}\text { Bar: } 93 \text { Restau- } \\
\text { rant: } 63\end{array}$ & 88 & 88 & 66 & 67 & 90 & 91 \\
\hline Study period & March-July 2015 & March-July 2016 & March-July 2016 & $\begin{array}{l}\text { July-November } \\
2017\end{array}$ & $\begin{array}{l}\text { April-October } \\
2018\end{array}$ & $\begin{array}{l}\text { May-September } \\
2018\end{array}$ & $\begin{array}{l}\text { May-September } \\
2018\end{array}$ \\
\hline
\end{tabular}

a Bar 1 in the previous studies is the same establishment as Bar A in the current studies

b In Study 1, wine glasses in current use in establishments were replaced in order to compare sales of wine when using $350 \mathrm{ml} \mathrm{glasses} \mathrm{to} \mathrm{sales} \mathrm{when} \mathrm{using} 450 \mathrm{ml}$ and $290 \mathrm{ml}$ glasses

c Following Study 1, this establishment updated their standard glass size from $310 \mathrm{ml}$ to $350 \mathrm{ml}$ Royal Leerdam Bouquet glasses

\section{Data analysis}

Protocol violations were recorded on eight out of 40 fidelity checks - one occasion in Study 2, two in Study 3, and five in Study 4. For three of these (one in each study), data collection was delayed by a week due to being unable to confirm changeover. In keeping with our plan of analysis, data for these three weeks were not used in the analyses.

Regression analyses predicted daily wine sales volume ( $\mathrm{ml}$ ) from glass size, modelled using dummy variables. Natural log was used as a variance stabilising transformation.

See Additional file 1 for further details on data analysis.

\section{Results}

Figure 1 shows the results of the main regression analyses for each comparison in each establishment (separated by restaurant and bars), controlling for various covariates. See Additional file 2 for unadjusted mean sales volume for each establishment under the different glass size conditions.

\section{Restaurant}

In the restaurant for Study 1, daily wine sales were $12.6 \%$ (95\% confidence interval (CI) $2.4 \%$ to $23.7 \%$ ) higher when $350 \mathrm{ml}$ glasses were used compared to $290 \mathrm{ml}$ glasses. A similar direction of effect was seen in Study 2 but was not statistically significant $(6.3 \%$ sales increase; $95 \% \mathrm{CI}$ $-1.4 \%, 14.7 \%)$. Daily wine sales were not significantly different in the restaurant when using $450 \mathrm{ml}$ glasses compared to $350 \mathrm{ml}$ glasses (Study 1: $7.6 \%$ decrease, 95\% CI $-17.7 \%$, 3.8\%; Study 2: $2.7 \%$ decrease, $95 \%$ CI $-10.6 \%, 5.9 \%)$. Daily wine glass sales were not significantly different when comparing $450 \mathrm{ml}$ glasses to $290 \mathrm{ml}$ glasses (Study 1: 4.1\% increase, 95\% CI $-5.0 \%$, 14.0\%; Study 2: $3.4 \%$ increase, $95 \%$ CI $-5.1 \%, 12.8 \%)$.

\section{Bars}

In Bar A (Study 3), daily wine sales were $21.4 \%$ (95\% CI $8.8 \%, 35.3 \%$ ) higher when sold using $450 \mathrm{ml}$ glasses compared to $350 \mathrm{ml}$ glasses. This effect was not observed in Bar B (Study 4), (6.9\% sales decrease, 95\% CI - 17.7\%, $5.4 \%)$. Daily wine sales were not significantly different in the bars when comparing $350 \mathrm{ml}$ glasses with $290 \mathrm{ml}$ glasses (Study 3: 7.4\% decrease, 95\% CI -21.6\%, 9.5\%; Study 4: $7.2 \%$ decrease, 95\% CI $-16.5 \%$, 2.9\%). Daily wine glass sales were not significantly different when comparing $450 \mathrm{ml}$ glasses to $290 \mathrm{ml}$ glasses (Study 3: $12.4 \%$ increase, $95 \%$ CI $-6.3 \%$, 34.9\%; Study 4: $-13.6 \%$ decrease, $95 \% \mathrm{CI}-25.4 \%$, 0\%).

\section{Discussion}

In the restaurant, sales of wine increased by $13 \%$ when served using $350 \mathrm{ml}$ glasses compared to $290 \mathrm{ml}$ in Study 1. This was not replicated in Study 2, and no other comparisons in the restaurant revealed any meaningful difference in sales. In the bars, sales of wine increased by $21 \%$ when served using $450 \mathrm{ml}$ glasses compared to $350 \mathrm{ml}$ glasses in Study 3. This was not replicated in Study 4 and 


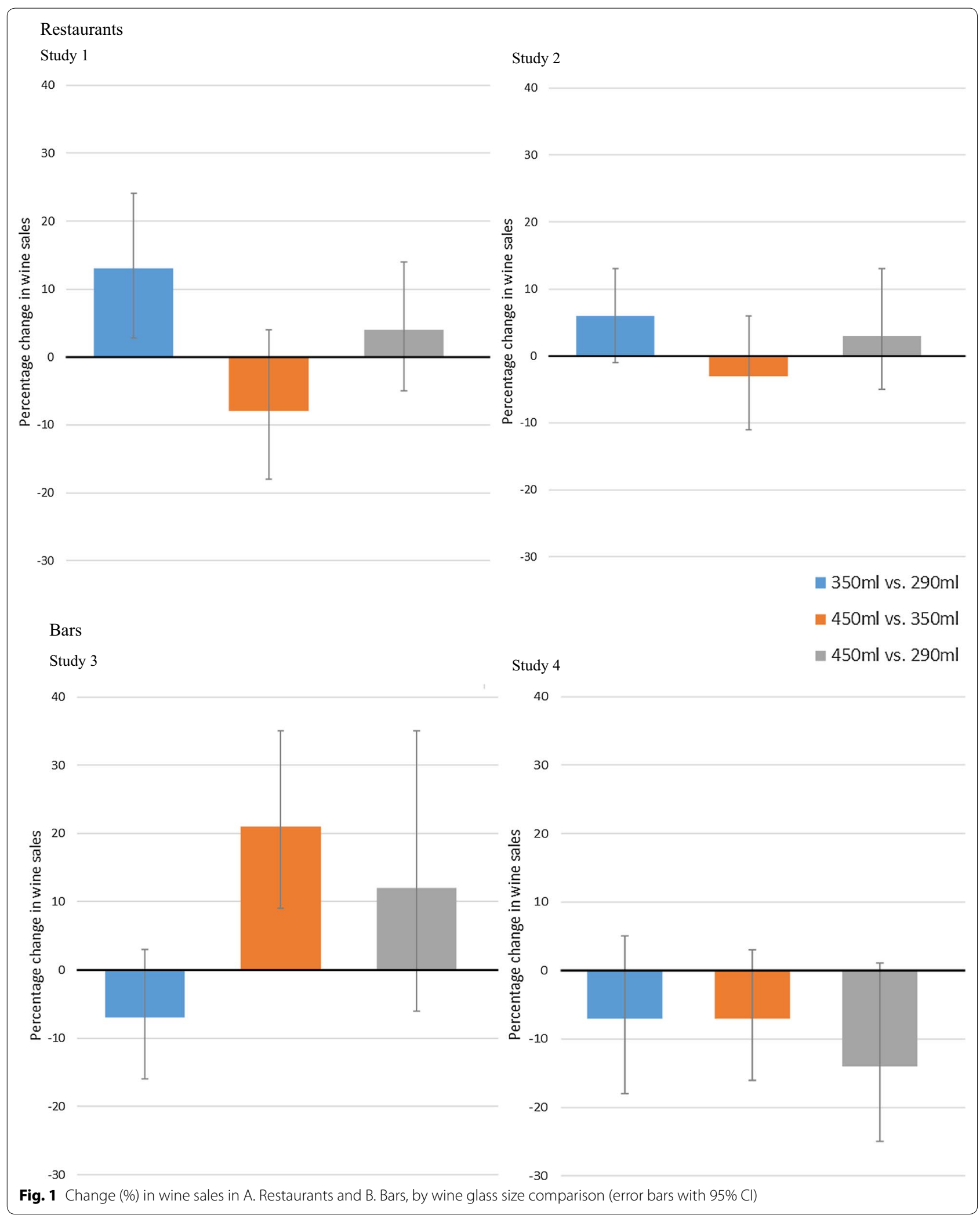


no other comparisons in the bars revealed any meaningful differences in sales. Although the expected association was absent in most of the comparisons, these results indicate a partial replication of previous studies showing that larger glasses increase wine sales $(7,8)$, as the only significant differences were in the expected direction and there was no evidence of decreases in sales with larger glasses. Previous studies have found similar inconsistencies, thus considerable uncertainty remains about the magnitude of the overall effects and the contexts in which they might occur.

There are a number of possible explanations for the inconsistent effects of glass size-across establishments and by glass comparison-observed in these studies. These include random fluctuations and context effects. First, it may be that increases in sales are wholly or partly a result of random fluctuations in purchasing behaviour, rather than representing effects of the intervention i.e. glass size. But if this were the case, some significant decreases in sales could also be expected, which is not evident from the results in the current or indeed previous studies.

Second, it may be that sales patterns are contextdependent and differ with characteristics of venues or, more broadly, between restaurants and bars. More wine was sold by the bottle in the restaurant than in the bars: $33 \%$ vs. $10 \%$. The effect of wine glass size may be greater in the context of wine freely poured from a bottle or carafe by staff or customers. In keeping with this, pouring inaccuracy increases with size of wine glass with larger glasses leading to more wine being poured [5]. Further research is required to assess this possible explanation, including examination of pouring inaccuracies with different glass sizes in naturalistic drinking settings.

Third, inconsistent effects may reflect differences between settings in available serving sizes. When purchasing by the glass, customers purchase a fixed measure of wine, thus any influence of glass size may be due to perceptual differences. In the restaurant, fixed measures of $125 \mathrm{ml}$ and $175 \mathrm{ml}$ were available, and the significant increase in sales occurred when comparing $350 \mathrm{ml}$ glasses to $250 \mathrm{ml}$ glasses. In the bars, fixed measures of $125 \mathrm{ml}, 175 \mathrm{ml}$ and $250 \mathrm{ml}$ were available, and the significant increase occurred when comparing $450 \mathrm{ml}$ glasses to $350 \mathrm{ml}$ glasses. Similarly, in one of these bars an increase of $10 \%$ was found with similar glass sizes $(510 \mathrm{ml}$ vs. $370 \mathrm{ml}$ ) in a previous study [8]. This might reflect an interaction between wine glass size and serving size, with perceptions of various serving sizes differing by glass size.

\section{Implications for research and policy}

Considerable uncertainty remains around the exact conditions under which larger wine glasses might increase sales given the current and previous findings. Given this uncertainty, reflecting a large number of different comparisons, a meta-analysis of all previous studies is an important next step in clarifying the effects on sales of altering wine glass size in restaurants and bars.

\section{Conclusions}

These results provide a partial replication of previous studies, generating some evidence in support of larger glasses increasing sales of wine under certain conditions and no evidence of an effect in the opposite direction. Further research is required to clarify the effects of glass size, the conditions under which the effect is largest and the mechanisms by which glass size influences sales.

\section{Limitations}

The strength of the studies presented here is that they add evidence to that generated from three previous field studies published in two articles, in a bar and restaurant setting [8] and two bars [9]. All these studies used objective outcomes assessing the impact of glass size on sales and considering potential covariates. The current research replicates the study design and method in the same bar (Study 3) as one of the previous studies [9] and in two further establishments, with a greater range of glass comparisons.

The results need to be interpreted in the context of several limitations. First, the primary outcome measure was wine sales, not actual consumption. Purchasing behaviour is, however, a valid proxy of consumption $[8,9]$ and a more practicable objective outcome measure in field settings [12]. Second, due to the nature of the field study, it was not possible to record characteristics of customers or details of their behaviour in the establishments. Third, the studies were conducted in a relatively affluent area of England, requiring more studies in other settings and populations. Finally, due to commercial constraints slightly different glass sizes were used in the current four studies compared to previous studies $(250 \mathrm{ml}, 300 \mathrm{ml}$, $370 \mathrm{ml}$ [7]; $300 \mathrm{ml}, 370 \mathrm{ml}$ and $510 \mathrm{ml}$ [8]). The lack of exact replications of the intervention characteristics, while unavoidable, makes it more difficult to compare and interpret findings.

\section{Additional files}

Additional file 1. "Detailed analysis outline" — further details on data analysis.

Additional file 2. "Daily wine sales (litres per day) for each establishment, by glass size [unadjusted mean (SD)]"- table showing unadjusted means of wine sales in each establishment. 


\section{Abbreviations}

Cl: confidence interval; TIPPME: Typology of Interventions in Proximal Physical Micro-Environments.

\section{Acknowledgements}

The authors thank the bar and restaurant staff for all their help in implement ing these studies. The authors thank Emily Blatchford, Saphsa Codling, Daina Kosīte, Tess Langfield, Ilse Lee, Emily Pechey, Milica Vasiljevic, Karen Vincent, and Sophie Wilcock for conducting fidelity to protocol checks. We are grateful to Anna Blackwell and Olivia Maynard for providing critical comments on an earlier version of this manuscript.

\section{Authors' contributions}

RP, TMM, MP, EM and GJH designed the study, and co-ordinated the intervention and data collection. MP analysed the study data. All authors were involved in interpreting the data. NC drafted the manuscript with considerable input from all authors. All authors read and approved the final manuscript.

\section{Funding}

This report is independent research commissioned and funded by the National Institute for Health Research Policy Research Programme (Policy Research Unit in Behaviour and Health (PR-UN-0409-10109: PI: Theresa Marteau)). Additional funding was provided by Wellcome Trust for Natasha Clarke's salary (a Collaborative Award in Science from Wellcome Trust (Behaviour Change by Design: 206853/Z/17/Z: Pls: Theresa Marteau, Paul Fletcher, Gareth Hollands and Marcus Munafò) and Rachel Pechey's salary (a Wellcome Research Fellowship in Society and Ethics [106679/Z/14/Z]).

The views expressed in this publication are those of the author(s) and not necessarily those of the funders. The funding bodies had no role in the design of the study and data collection, analyses, and interpretation of data or in writing of the manuscript.

\section{Availability of data and materials}

All studies were pre-registered (Study 1: ISRCTN17958895: https://doi. org/10.1186/ISRCTN17958895; Open Science Framework: https://osf.io/k9ucd /. Study 2: ISRCTN17097810: https://doi.org/10.1186/ISRCTN17097810; Open Science Framework: https://osf.io/653te/. Study 3 and 4: ISRCTN39401124: https://doi.org/10.1186/ISRCTN39401124; Open Science Framework: https:// osf.io/m5qb9/). Data are commercially sensitive, and were provided by bars on the understanding that these would not be made available beyond the research team

\section{Ethics approval and consent to participate}

Ethical approval was obtained from the University of Cambridge Research Ethics Committee (Pre.2017.035). Consent was not sought from customers as knowledge of the intervention could have impacted on the outcome. No compensation was offered to the restaurant or bars.

\section{Consent for publication}

Not applicable.

\section{Competing interests}

The authors declare that they have no competing interests.

Received: 2 May 2019 Accepted: 12 July 2019

Published online: 17 July 2019

\section{References}

1. James SL, et al. Global, regional, and national incidence, prevalence, and years lived with disability for 354 diseases and injuries for 195 countries and territories, 1990-2017: a systematic analysis for the Global Burden of Disease Study 2017. Lancet. 2018;392(10159):1789-858.

2. Steel N, et al. Changes in health in the countries of the UK and 150 English Local Authority areas 1990-2016: a systematic analysis for the Global Burden of Disease Study 2016. Lancet. 2018;392(10158):1647-61.

3. Hollands GJ, et al. Portion, package or tableware size for changing selection and consumption of food, alcohol and tobacco. Cochrane Database Syst Rev. 2015;9:CD011045.

4. Kerr WC, Patterson D, Koenen MA, Greenfield TK. Large drinks are no mistake: glass size, not shape, affects alcoholic beverage drink pours. Drug Alcohol Rev. 2009;28(4):360-5.

5. White AM, Kraus CL, McCracken LA, Swartzwelder HS. Do college students drink more than they think? Use of a free-pour paradigm to determine how college students define standard drinks. Alcohol Clin Exp Res. 2003;27(11):1750-6.

6. Pechey $R$, et al. Does glass size and shape influence judgements of the volume of wine? PLOS ONE. 2015;10(12):e0144536.

7. Geier AB, Rozin P, Doros G. Unit bias. A new heuristic that helps explain the effect of portion size on food intake. Psychol Sci. 2006;17(6):521-5.

8. Pechey R, Couturier D-L, Hollands GJ, Mantzari E, Munafò MR, Marteau TM. Does wine glass size influence sales for on-site consumption? A multiple treatment reversal design. BMC Public Health. 2016;16(1):390.

9. Pechey R, Couturier D-L, Hollands GJ, Mantzari E, Zupan Z, Marteau TM. Wine glass size and wine sales: a replication study in two bars. BMC Res Notes. 2017; 10(1):287

10. UK Government. Weights and measures: the law. 2016; https://www. gov.uk/weights-measures-and-packaging-the-law/specified-quantities. Accessed Jan 52017.

11. Hollands GJ, et al. The TIPPME intervention typology for changing environments to change behaviour. Nature Hum Behav. 2017;1:0140.

12. Troy DM, Maynard OM, Hickman M, Attwood AS, Munafò MR. The effect of glass shape on alcohol consumption in a naturalistic setting: a feasibility study. Pilot Feasibility Stud. 2015;1(1):27.

\section{Publisher's Note}

Springer Nature remains neutral with regard to jurisdictional claims in published maps and institutional affiliations.

Ready to submit your research? Choose BMC and benefit from:

- fast, convenient online submission

- thorough peer review by experienced researchers in your field

- rapid publication on acceptance

- support for research data, including large and complex data types

- gold Open Access which fosters wider collaboration and increased citations

- maximum visibility for your research: over 100M website views per year

At $B M C$, research is always in progress.

Learn more biomedcentral.com/submissions 